\title{
Insertion of magnetically controlled growing rods in a patient with a diaphragmatic pacemaker: case report
}

\author{
Andrew C. Vivas, MD, ${ }^{1,2}$ Steven W. Hwang, MD, ${ }^{1}$ and Joshua M. Pahys, MD1 \\ ${ }^{1}$ Shriners Hospitals for Children-Philadelphia, Pennsylvania; and 'Department of Neurosurgery, University of South Florida, \\ Tampa, Florida
}

\begin{abstract}
Phrenic stimulators offer an alternative to standard mechanical ventilation as well as the potential for ventilator independence in select patients with chronic respiratory failure. Young patients ( $<10$ years old) with high cervical spinal cord injuries often develop paralytic scoliosis due to loss of muscle tone caudal to their spinal cord lesion. Growing rod systems allow for stabilization of spinal deformity while permitting continued growth of the spine and thoracic cavity. Magnetically controlled growing rods (MCGRs) offer the advantage of noninvasive expansion, as opposed to the operative expansion required in traditional growing rod systems. To the authors' knowledge, this is the first reported case of MCGRs in a patient with a diaphragmatic pacemaker (DP). A 7-year-old boy with ventilator dependence after a high cervical spinal cord injury presented to the authors' institution with paralytic scoliosis that progressed to $>120^{\circ}$. The patient had previously undergone insertion of phrenic nerve stimulators for diaphragmatic pacing. The decision was made to insert MCGRs bilaterally to stabilize his deformity, because the planned lengthening surgeries that are necessary with traditional growing rods would be poorly tolerated in this patient. The patient's surgery and postoperative course were uneventful. The DP remained functional after insertion and lengthening of the MCGRs by using the external magnet. The DP had no effect on the expansion capability of the MCGRs. In conclusion, the MCGRs appear to be compatible with the DP. Further studies are needed to validate the long-term safety and compatibility of these 2 devices.
\end{abstract}

https://thejns.org/doi/abs/10.3171/2017.7.FOCUS17356

KEY WORDS magnetically expandable growing rod; early-onset scoliosis; spinal cord injury; phrenic nerve stimulator; diaphragmatic pacemaker

$\mathrm{S}$ KELETALLY immature patients with progressive spinal deformity are commonly treated using "growthguiding instrumentation." Options for growth guidance include traditional growing rods and the more recently introduced magnetically controlled growing rods (MCGRs). Both constructs allow for spinal deformity correction and continued growth of the spine and thorax in patients with severe, progressive, early-onset scoliosis.

Patients with respiratory failure due to chronic hypoventilation syndrome, high cervical spinal cord injury (SCI), or progressive neurodegenerative conditions may be candidates for diaphragmatic pacemakers (DPs). A DP may allow patients to be partially or completely weaned off of mechanical ventilation, potentially improving their quality of life and minimizing complications associated with long-term positive-pressure ventilation.

It is unclear whether the lengthening mechanism in the MCGR is compatible with indwelling devices like DPs. We present the case of a patient with a DP who underwent insertion and postoperative lengthening of bilateral MCGRs without adverse effects to the DP.

\section{Case Report}

History and Examination

A 7-year-old boy presented to our institution with severe paralytic thoracolumbar scoliosis, pelvic obliquity, and complete ventilator dependence secondary to a C2-3 level complete SCI sustained at the age of 2 years after a motor vehicle accident (Fig. 1). To reduce his time on mechanical ventilation, the patient had undergone insertion of a DP 2 years previously at our institution, and was using the DP to pace his breathing for 2-3 hours per day off of his ventilator. Unfortunately, the patient's deformity had progressed to $>120^{\circ}$ despite bracing, and he lost the ability to sit upright. Because his thoracic height was $12 \mathrm{~cm}$ and well below the desirable volume and height, surgical intervention with growing instrumentation was recommended. A multidisciplinary team concluded that MCGRs offered the best option for minimizing future invasive interventions, stabilizing the spinal deformity, and maximizing future spinal and thoracic growth. The family was informed that the use of MCGRs in a patient with a

ABBREVIATIONS DP = diaphragmatic pacemaker; MCGR = magnetically controlled growing rod; $\mathrm{SCl}=$ spinal cord injury.

SUBMITTED June 1, 2017. ACCEPTED July 11, 2017.

INCLUDE WHEN CITING DOI: 10.3171/2017.7.FOCUS17356. 


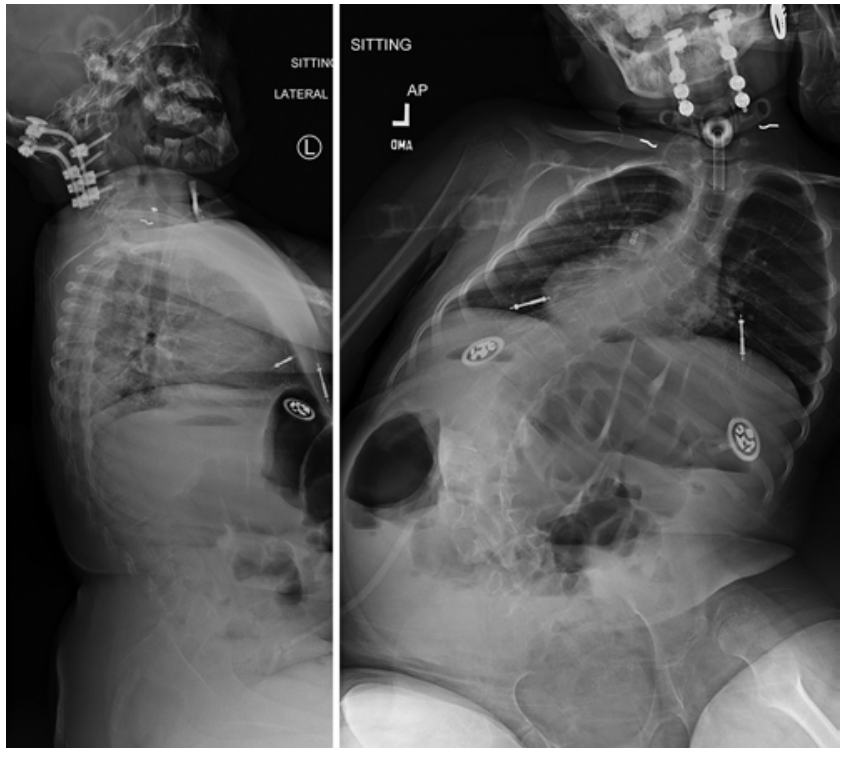

FIG. 1. Anteroposterior (right) and lateral (left) upright sitting radiographs showing $115^{\circ}$ thoracolumbar levoscoliosis and severe pelvic obliquity.

preexisting, radiofrequency-controlled DP was physician directed (i.e., "off-label").

\section{Operation and Postoperative Course}

The patient underwent insertion of bilateral MCGRs (MAGEC Rod; NuVasive, Inc.) from T-3 to the sacrum. His surgery and postoperative course were unremarkable (Fig. 2). Because the patient had only used the DP device for 2-3 hours per day prior to surgery, the device was not required for routine ventilation. Therefore, the patient received mechanical ventilation during surgery and immediately postoperatively, until it was thought that he was stable enough for a trial of respirations off the ventilator with the aid of the DP device. As a precautionary procedure, the MCGR's external magnet was placed on the patient's back prior to surgery to simulate an MCGR lengthening. The DP device was able to function properly after this maneuver, and thus we believed that the DP would probably not be affected by the external magnet. At postoperative Day 3 the patient began using his DP without issue, and the device was functioning normally. At postoperative Day 7, the MCGRs were expanded using the external magnet. Both devices remained functional at the 6-month follow-up appointment.

\section{Discussion}

Electrophrenic ventilation, or phrenic nerve stimulation with DPs, is an alternative to mechanical ventilation in patients with respiratory failure. ${ }^{4}$ Radiofrequency programmers allow external control of the rate and amplitude of diaphragmatic stimulation. In the appropriate patient, electrophrenic ventilation offers a safe, potentially costeffective option for decreasing ventilator dependence and improving quality of life. ${ }^{3,5,7,20}$ Primary indications for phrenic stimulation include central hypoventilation syndrome (Ondine's curse) and high cervical SCI. ${ }^{11}$
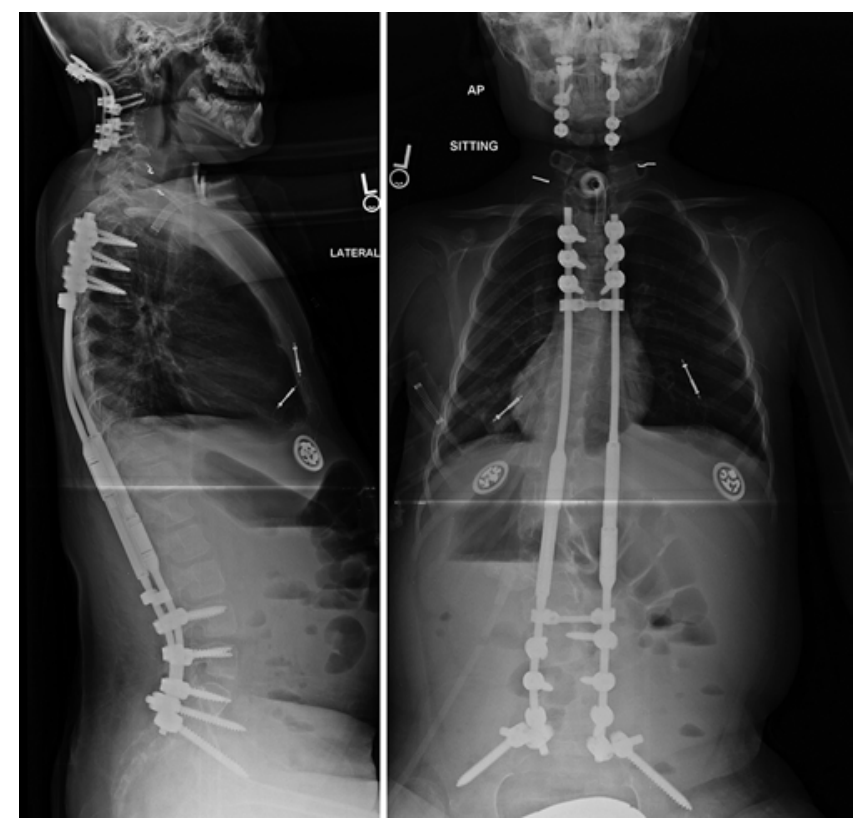

FIG. 2. Anteroposterior (right) and lateral (left) upright sitting radiographs obtained after insertion of bilateral MCGRs in the patient.

Young children (age $<8$ years) are particularly susceptible to high cervical SCI after trauma, and subsequent respiratory failure., ${ }^{9,12,14,16}$ Pediatric patients with SCI, especially those who are skeletally immature, commonly develop paralytic scoliosis due to loss of truncal tone caudal to the injury. ${ }^{14}$ In a retrospective review by Dearolf and colleagues, ${ }^{2}$ the rate of scoliosis after SCI in skeletally immature patients was found to be $97 \%$, compared with $52 \%$ in patients injured after the growth spurt. Deformity in patients with tetraplegia may subsequently lead to uneven weight distribution and poor sitting balance, predisposing them to decubitus ulcers and a tendency to slide out of the sitting position. ${ }^{17}$

Surgical treatment of deformity is challenging in this population, because definitive fusion prior to skeletal maturity may lead to pulmonary restriction due to a diminished thoracic cavity (i.e., thoracic insufficiency syndrome). ${ }^{1,13}$ Skeletally immature patients with progressive deformities are often treated using "growth-friendly instrumentation" to allow continued spine and chest growth and curve stabilization. ${ }^{21}$ The MCGR offers the advantage of noninvasive rod expansion, as opposed to traditional growing rods..$^{10}$ These rods are expanded using an external magnet. Early results on the outcome and efficacy of MCGRs are promising. $6,8,15,18,19$

The use of an MCGR in a patient with preexisting phrenic stimulators has not been studied. Our patient received primarily mechanical ventilation and would not have a significant functional decline if the DP were compromised by the MCGR. We believed that the external magnet used to lengthen the MCGR would not affect the phrenic stimulator, which uses a radiofrequency programmer and not an external magnet. The use of an MCGR in a patient with an indwelling device (i.e., cardiac pacemaker, vagal nerve stimulator, programmable CSF shunts, and so on) that contains metallic and/or magnetic components is 
not supported by the manufacturer at this time. There have been no reports to date to evaluate the efficacy and safety of MCGR placement in a patient with an indwelling device. The manufacturers of the DP and the MCGR were contacted prior to surgery regarding placement of MCGRs in a patient with a radiofrequency-controlled DP. Due to the small amount of metal present in the leads of the DP, the companies were unable to support the use of MCGRs in this patient. Thus, the placement of MCGRs in this patient with a phrenic pacemaker was physician directed, and therefore off-label.

The results of this study are not applicable to the use of an MCGR with magnetically controlled indwelling devices (i.e., cardiac pacemaker, vagal nerve stimulator, programmable CSF shunts, and so on). The DP is controlled by radiofrequency and is not magnetic, containing only a small amount of metal in the leads. We therefore believed that there was a low likelihood of any potential deleterious effect to the patient or the DP with the placement of MCGRs in this patient.

The patient was monitored for 1 week postoperatively to ensure continued function of the DP. At discharge, the parents were instructed to use a pulse oximeter whenever the child was using the DP to wean off of mechanical ventilation. The MGCR construct has been successfully lengthened in the outpatient setting and the DP device remains functional.

\section{Conclusions}

The MCGR construct appears to be compatible with the DP. Further studies are needed to validate the longterm safety and compatibility of these 2 devices.

\section{References}

1. Akbarnia BA: Management themes in early onset scoliosis. J Bone Joint Surg Am 89 (Suppl 1):42-54, 2007

2. Dearolf WW III, Betz RR, Vogel LC, Levin J, Clancy M, Steel HH: Scoliosis in pediatric spinal cord-injured patients. J Pediatr Orthop 10:214-218, 1990

3. Elefteriades JA, Quin JA, Hogan JF, Holcomb WG, Letsou GV, Chlosta WF, et al: Long-term follow-up of pacing of the conditioned diaphragm in quadriplegia. Pacing Clin Electrophysiol 25:897-906, 2002

4. Garara B, Wood A, Marcus HJ, Tsang K, Wilson MH, Khan M: Intramuscular diaphragmatic stimulation for patients with traumatic high cervical injuries and ventilator dependent respiratory failure: a systematic review of safety and effectiveness. Injury 47:539-544, 2016

5. Garrido-Garcia H, Mazaira Alvarez J, Martín Escribano P, Romero Ganuza J, La Banda F, Gambarrutta C, et al: Treatment of chronic ventilatory failure using a diaphragmatic pacemaker. Spinal Cord 36:310-314, 1998

6. Hickey BA, Towriss C, Baxter G, Yasso S, James S, Jones A, et al: Early experience of MAGEC magnetic growing rods in the treatment of early onset scoliosis. Eur Spine J 23 (Suppl 1):S61-S65, 2014

7. Hirschfeld S, Exner G, Luukkaala T, Baer GA: Mechanical ventilation or phrenic nerve stimulation for treatment of spinal cord injury-induced respiratory insufficiency. Spinal Cord 46:738-742, 2008

8. Hosseini P, Pawelek J, Mundis GM, Yaszay B, Ferguson J, Helenius I, et al: Magnetically controlled growing rods for early-onset scoliosis: a multicenter study of 23 cases with minimum 2 years follow-up. Spine (Phila Pa 1976) 41:1456-1462, 2016

9. Jain A, Brooks JT, Rao SS, Ain MC, Sponseller PD: Cervical fractures with associated spinal cord injury in children and adolescents: epidemiology, costs, and in-hospital mortality rates in 4418 patients. J Child Orthop 9:171-175, 2015

10. Jenks M, Craig J, Higgins J, Willits I, Barata T, Wood H, et al: The MAGEC system for spinal lengthening in children with scoliosis: a NICE Medical Technology Guidance. Appl Health Econ Health Policy 12:587-599, 2014

11. Khong P, Lazzaro A, Mobbs R: Phrenic nerve stimulation: the Australian experience. J Clin Neurosci 17:205-208, 2010

12. Kokoska ER, Keller MS, Rallo MC, Weber TR: Characteristics of pediatric cervical spine injuries. J Pediatr Surg 36:100-105, 2001

13. Mayer O, Campbell R, Cahill P, Redding G: Thoracic insufficiency syndrome. Curr Probl Pediatr Adolesc Health Care 46:72-97, 2016

14. Parent S, Mac-Thiong JM, Roy-Beaudry M, Sosa JF, Labelle $\mathrm{H}$ : Spinal cord injury in the pediatric population: a systematic review of the literature. J Neurotrauma 28:1515-1524, 2011

15. Polly DW Jr, Ackerman SJ, Schneider K, Pawelek JB, Akbarnia BA: Cost analysis of magnetically controlled growing rods compared with traditional growing rods for early-onset scoliosis in the US: an integrated health care delivery system perspective. Clinicoecon Outcomes Res 8:457-465, 2016

16. Roche C, Carty H: Spinal trauma in children. Pediatr Radiol 31:677-700, 2001

17. Sansam KA: Controversies in the management of traumatic spinal cord injury. Clin Med (Lond) 6:202-204, 2006

18. Teoh KH, Winson DM, James SH, Jones A, Howes J, Davies PR, et al: Do magnetic growing rods have lower complication rates compared with conventional growing rods? Spine J 16 (4 Suppl):S40-S44, 2016

19. Thompson W, Thakar C, Rolton DJ, Wilson-MacDonald J, Nnadi C: The use of magnetically-controlled growing rods to treat children with early-onset scoliosis: early radiological results in 19 children. Bone Joint J 98-B:1240-1247, 2016

20. Weese-Mayer DE, Silvestri JM, Kenny AS, Ilbawi MN, Hauptman SA, Lipton JW, et al: Diaphragm pacing with a quadripolar phrenic nerve electrode: an international study. Pacing Clin Electrophysiol 19:1311-1319, 1996

21. Yang JS, McElroy MJ, Akbarnia BA, Salari P, Oliveira D, Thompson GH, et al: Growing rods for spinal deformity: characterizing consensus and variation in current use. J Pediatr Orthop 30:264-270, 2010

\section{Disclosures}

Dr. Hwang reports being on the speaker's bureau at Zimmer Biomet. Dr. Pahys reports being a consultant for DePuy Synthes Spine, Globus Medical, and Zimmer Biomet.

\section{Author Contributions}

Conception and design: Pahys, Vivas. Acquisition of data: Pahys, Vivas. Analysis and interpretation of data: Pahys, Vivas. Drafting the article: Pahys, Vivas. Critically revising the article: all authors. Reviewed submitted version of manuscript: all authors. Approved the final version of the manuscript on behalf of all authors: Pahys. Study supervision: Pahys.

\section{Correspondence}

Joshua M. Pahys, Shriners Hospitals for Children-Philadelphia, 3551 North Broad St., 8th Fl., Philadelphia, PA 19140. email: jpahys@shrinenet.org. 